\title{
The Coconut Industry: A Review of Price Forecasting Modelling in Major Coconut Producing Countries
}

\author{
M.G.D Abeysekara ${ }^{1}$ and K.P Waidyarathne ${ }^{2}$
}

\begin{abstract}
The global supply and demand for coconuts and coconut-based products have increased tremendously over the past decades; hence, the industry has become one of the significant contributors to the economies of producer countries. However, similar to the other agricultural commodities, coconut has also been confronted by fluctuation in prices and thus accords importance for a reliable price modelling and forecasting techniques to ease the burden on the value chain actors. Therefore, the objective of this paper is to review the main approaches used in modelling and forecasting coconut prices, with an assessment of the strengths and weaknesses of each approach. The modelling techniques used in coconut price forecasting were mainly time series models dominated by univariate time series models. This type of models excessively confines the analysis to a single variable, despite the many interactions affected in a system of coconut pricing. The major drawback in existing price modelling studies is the absence of interacting factors such as prices, production, climatic variables, their interactions and the external factors as a system. Therefore, it is important to integrate the existing studies of coconut price modelling and forecasting with a system's approach by including other influencing variables to generate more realistic forecast values, allowing the industry to adopt its changing circumstances.
\end{abstract}

Key words: Coconut, modelling, price forecasting, time series models, system's approach

\section{Introduction}

Coconut (Cocos nucifera L.) is a versatile perennial tree crop with very important food value and other endless uses which pave the way for the emergence of a diversified set of industrial activities. Owing to the multifarious uses of different parts of the palm, it forms an integral component of the social, economic and cultural lives of nearly 80 million people in 92 countries (Naveena, et al., 2014). The economic importance of the coconut industry is manifold as well as a vital source of export earnings for the coconut producing countries. Coconut production is heavily confined to the Asia and Pacific region and the major producers in the world are Indonesia, Philippines, India, Sri Lanka and Brazil whereas the consumption is dispersed around the globe (Asian Pacific Coconut Community, 2016). During the past decade, the global demand for coconut had grown significantly (Figure 1) due to the increasing emphasis being placed on coconut water and Virgin Coconut Oil (VCO) due to their recently discovered health benefits (Rethinam, 2005). Moreover, strong niche markets are also emerging for coconut milk, coconut cream, coconut-based snacks, as well as coconut flour and coconut sugar, while the demand for traditional desiccated coconut and copra remains relatively stable (Sri Lanka Export Development Board, 2017). This driving up demand for the coconut-based products in the world market has created the derived demand for fresh coconuts.

Coconut needs price stability as a pre-requisite for its steady growth, because of its inability to short-run adjustments to price fluctuations unlike the seasonal and annual crops (Das, 1986). Being essentially a smallholder crop accounted for nearly 80 percent of the total holdings in major producer countries (Kalidas, et al., 2014; Pathiraja, et al., 2015), it further stresses the importance of having a stable price for the benefit of farmers' livelihood.

\footnotetext{
${ }^{1}$ Agricultural Economics and Agribusiness Management Division, Coconut Research Institute, Sri Lanka. (abeysekaradilini@gmail.com)

${ }^{2}$ Plant Physiology Division, Coconut Research Institute, Sri Lanka. (Corresponding Author: pramuditha. waidyarathne@gmail.com)
} 


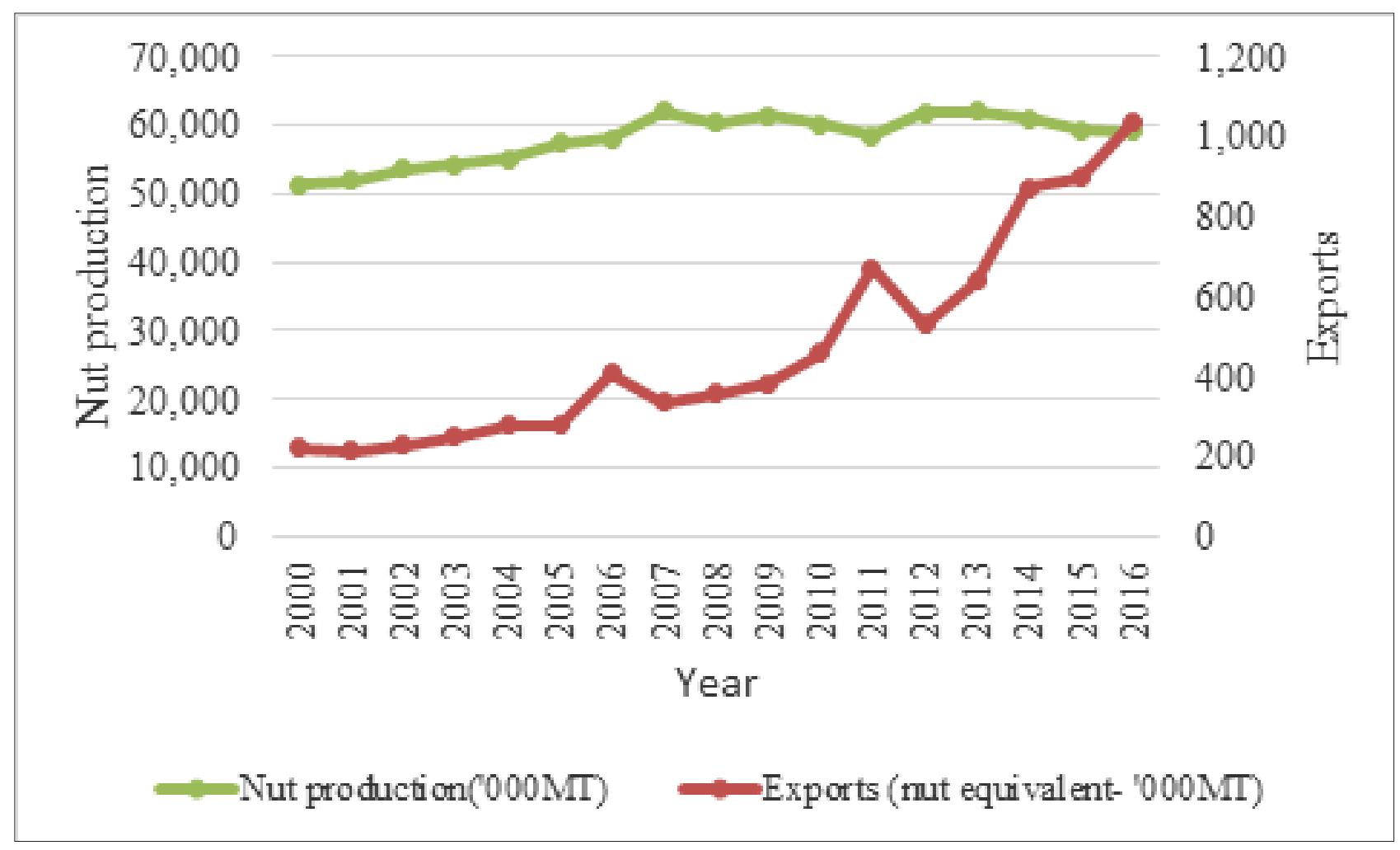

Figure 1. World production and export quantities of fresh coconuts from 2000-2016 (FA0, 2017)

Rainfall and temperature are the major climatic factors influencing the coconut yield (Peiris, et al., 1995). Coconut production fluctuates due to immediate and lagged effects of adverse weather conditions resulting in instability of coconut prices. The consequences of such unusual price fluctuations are negative on the industry. For example, wide variations in prices erode the purchasing power of consumers, producers may also get wrong decisions and finally, the impact might make costly outcomes (Abeygunawardena, et al., 1996). Moreover, due to this characteristic uncertainty in the prices of coconuts and their products, the coconut industry has been trapped in a vicious cycle, a circle of low investment leading to low productivity and low return leading to low investment again and thus reinforcing themselves through a feedback loop.

Since economic conditions and consequently prices and price relations are ever changing, business judgments are based largely upon forecasts. The coconut industry itself also has come into a situation similar to the other agricultural commodities, where the prices are determined by both domestic and international market forces while leading to an increase in price variability, and accords importance to reliable price modelling and forecasting techniques (Jha and Sinha, 2013). Therefore, the objective of this paper is to review the main approaches used by the agricultural forecasters in modelling and forecasting coconut prices, with an assessment of the strengths and weaknesses of each approach. Some other relevant price models (of other crops) were also examined to see how the existing coconut price models were improved by approaches used in those models.

\section{A Brief History}

\section{Agriculture Economics and Price Forecasting in a Nutshell}

A scientific forecast is one made on the basis of a discovered systematic sequence of normal experience (Taylor, 1924). Forecasting is not a novel concept in agricultural economics, as it is one of the fundamental components of agricultural commodity trading. Consequently, price analysis and empirical modeling of price determination processes play a central role in research on agricultural markets. Therefore, forecasts of agricultural production and prices have been at the forefront of debate and controversy for over decades since the twentieth century (Allen, 1994; Li, et al., 2010) and it has been studied extensively since then. 
There is a long history of econometric analysis starting with the partial analysis of a single commodity sector using single equation studies, which were then followed by multiequation, multi-sectorial econometric studies. Expansion of the agricultural economic research towards forecasting production/ prices and estimating elasticity using econometric approaches were evident over the second quarter century from the existence of agricultural economics profession (Just, 1993). With the expansion of the complexity and flexibility of econometrics paradigm in the third quarter century, research focus had been moved towards policy, trade and environment and resource economics. To date, the dominant focus of agriculture economics research is on supply modelling, where most agriculture forecasting belongs.

The nature of the agricultural production and the historical relationship among the different groups of participants have made the agriculture different from most economic activities. Therefore, agricultural price modelling is different from modelling of non-farm goods and services (Allen, 1994). Production and prices of agricultural commodities are largely influenced by eventualities. Consequently, prices are unpredictable in case of natural calamities and hence, they are often random leadings to considerable risk and uncertainty in the process of agricultural price modelling and forecasting.

There are two commonly used basic approaches to forecasting in the literature. Those are structural models, which proceed from the first principle of consumer and producer theory, and time series models, where past observations of the same variable are analyzed to develop a model describing the underline relationships (Jha and Sinha, 2013). Agricultural application of modern time series methods did not appear till the 1970s; hence, price forecasts were largely made by conventional econometric methods in the earlier studies (Allen, 1994). However, during the past few decades, much effort has been devoted to the development and improvement of time series forecasting models (Jha and Sinha, 2013) and correspondingly, the methods have become increasingly complex. Meanwhile, comparing the forecasts from different methods were also progressed and quantitative accuracy with small errors, along with the turning point of forecasting power was considered for evaluating forecasting models.

\section{Price modelling related to the coconut industry (fresh coconuts and coconut-based products)}

Price forecasting of agricultural commodities has been extensively studied over decades and several different models have been developed (Li, et al., 2010). There is a considerable number of studies related to the coconut sector where similar modelling approaches have been applied. Table 1 summarizes the relevant literature on different approaches used for forecasting prices of fresh coconuts and coconut-based products.

The modelling technique that has been widely used in the literature to model coconut and other coconut products are time series models. The use of structural models describing how the future values of coconut prices are affected by specific economic drivers were hardly found in the literature. It appears that even though the structural models provide valuable insights into the determinants of commodity price movements, the contemporary picture is different in the reality. This may be due to the computational complexity and high data requirement of structural price forecasting models than time series models, which require less arduous data for consistent and up-todate forecasting.

Abeygunawardena, et al., (1996) appeared to be the first and only group of researchers who forecasted one year ahead of retail and wholesale prices of coconut with a VAR model, a stochastic process model that captures the linear interdependencies among multiple time series, using twenty-year period monthly data (1973-1992). They have tested two models considering the explanatory power of the concerned variables. The first model is a twovariables VAR model defined by endogenous variables, retail and wholesale prices, where the second model, VAR-X, is an extension of the first adding lagged rainfall as an exogenous variable. According to their findings, the data was best fitted to the first model and one year ahead forecasts made using the model were statistically accepted. Moreover, they have concluded that though there is a lagged effect of rainfall on coconut yield, it has not contributed significantly on nut prices according to the model statistics. Even though, their results were in favor of two-variables VAR model, they have stressed on the importance of concentrating on developing a composite forecast model to make a better forecast for the future. More importantly, 


\begin{tabular}{|c|c|c|}
\hline Variable/s & Modelling approaches tested & Reference \\
\hline $\begin{array}{l}\text { Monthly retail and wholesale } \\
\text { prices of coconuts in Sri Lanka }\end{array}$ & $\begin{array}{l}\text { BVAR } \\
\text { MVAR }\end{array}$ & Abeygunawardena, et al., (1996) \\
\hline $\begin{array}{l}\text { Monthly producer and retail } \\
\text { prices of coconuts in Sri Lanka }\end{array}$ & $\begin{array}{l}\text { GARCH } \\
\text { NARX }\end{array}$ & Priyadarshani, et al., (2014) \\
\hline $\begin{array}{l}\text { Monthly coconut oil prices at } \\
\text { Cochin market }\end{array}$ & $\begin{array}{l}\text { TAR } \\
\text { TARCH }\end{array}$ & $\begin{array}{l}\text { Nampoothiri \& Balakrishna,(2000) } \\
\text { Nampoothiri, (2001) }\end{array}$ \\
\hline $\begin{array}{l}\text { National average prices of DC } \\
\text { and CO, Retail and wholesale } \\
\text { prices of fresh nuts }\end{array}$ & $\begin{array}{l}\text { General Decomposition } \\
\text { MA } \\
\text { Double Exponential Smoothing } \\
\text { Single Exponential Smoothing } \\
\text { ARIMA }\end{array}$ & Rangoda, et al., (2006) \\
\hline $\begin{array}{l}\text { Monthly average prices of } \\
\text { coconut, coconut oil and copra in } \\
\text { three markets in India }\end{array}$ & $\begin{array}{l}\text { Exponential smoothing methods } \\
\text { HWMS } \\
\text { SARIMA } \\
\text { ANN }\end{array}$ & Indraji, (2014) \\
\hline $\begin{array}{l}\text { Annual prices of tea, rubber and } \\
\text { coconut in Sri Lanka }\end{array}$ & $\begin{array}{l}\text { ARIMA } \\
\text { VECM }\end{array}$ & Nyantakyi, et al., (2015) \\
\hline Monthly global prices of copra & TARMO & Ang, (2016) \\
\hline $\begin{array}{l}\text { Monthly average prices of } \\
\text { coconut oil, copra and oil cake in } \\
\text { Kochi }\end{array}$ & $\begin{array}{l}\text { HWMS } \\
\text { SARIMA }\end{array}$ & Elias, (2018) \\
\hline $\begin{array}{l}\text { Monthly wholesale price of } \\
\text { coconut oil }\end{array}$ & ARIMA & Priyanga, et al., (2019) \\
\hline
\end{tabular}

Table 1. Summary of the coconut price modelling techniques in the literature (The best model is shown with the bold letters)

* (BVAR - Bivariate Vector Autoregression, MVAR - Multiple Vector Autoregression, TAR - Threshold Auto Regressive, TARCH - Threshold Auto Regressive Conditional Heteroskedastic, MA- Moving Average, ARIMA - AutoRegressive Integrated Moving Average, HWMS - Holt-Winters Multiplicative Seasonal model, SARIMA - Seasonal AutoRegressive Integrated Moving Average, ANN - Artificial Neural Network, GARCH - Generalized Auto Regressive Conditional Heteroskedastic, NARX - Nonlinear Autoregressive Exogenous, VECM - Vector Error Correction Model, TARMO Time Series Regression with ARIMA Noise, Missing Observations, and Outliers)

they have deflated both time series using food values of the Colombo Consumer Price Index and have used the prices in real terms for the analysis. Even though much of economics is about the consequences of changes in relative prices, sometimes theory and logic provide only general guides for empirical analyses that use relative prices. Therefore, the choice of deflators of commodity prices can change the time-series properties of the original series hence that could significantly impact empirical results (Deaton and Laroque, 1992; Harvey, 1993; Peterson and Tomek, 2000).

Another modelling attempt was made by Nampoothiri \& Balakrishna (2000) to fit a TAR model to forecast monthly coconut oil prices using data from Cochin market, India from January 1978 to December 1996. They have concluded that the presence of non-linearity in the monthly oil prices series was well explained by a threshold model compared to a simple autoregressive (AR) model. However, later in 2001, the same authors (Nampoothiri, 2001) reported that wide and violent fluctuations existed on the same time series data were better handled by a composite model, which combined the TAR with an Auto Regressive Conditional Heteroskedasticity (ARCH) effect. This may be due to the presence of asymetric volatility in stock returns and a changing conditional variance of the time series. Notably, these two studies were focused on how a set of real data can be applied to different time series models 
rather than modelling the coconut oil prices. This an example of showing the improvement of model accuracy by improving the dimensions of the modelling approach. TAR models perform better than AR because they handle nonlinearity in the data as piece-wise linear models assuming that there are more than one linear regime in the observed data series. This has added new dimension to the simple linear AR process. Further improvement of TAR model structure with ARCH effect to represent the volatility jointly in a single schema enhances the applicability of the model.

Rangoda et al. (2006) have employed a range of conventional time series models including; general decomposition method, MA, HWMS, Single Exponential Smoothing method (SES), Double Exponential Smoothing method (DES) and ARIMA method to find the appropriate model to forecast prices of coconut and allied products. National average prices of desiccated coconut, coconut oil, and average retail and wholesale prices of fresh coconuts from January 1974 to December 2004 was used in the study. By considering the lowest MAPE, MAD and MSD, authors have concluded that ARIMA and single exponential smoothing method were better than other models to predict prices of fresh coconut, coconut oil and desiccated coconut. Of the methods tested, MA and SES techniques cannot be applied successfully when the data series show trends and seasonality but authors claimed that the magnitude of seasonal fluctuations and the positive trend of prices of the three products considered in the study were remarkably higher after the year 1983 compared to the preceding period.

Indraji (2014) attempted to model monthly prices of coconut oil and copra in Alappuzha, Kochi and Kozhikode markets in India from January 1990 to December 2015 and coconut prices at Alppuzha from January 1998 to December 2015. ARIMA, ANN and several different exponential smoothing models (SES, DES, Holt-Winters' additive (HWAS) and multiplicative) were employed on the study. Their analysis suggested that HWMS model was the best among the other fitted models in many occasions. Monthly prices of coconut oil, copra and coconut oil cake of Kochi market from January 1995 to December 2010 were reanalyzed by Elias (2018) using Holt-Winters Additive Exponential Smoothing and Seasonal ARIMA methods and claimed that Holt- Winter's method provided the best forecasting model. HWMS is among the most widely and successfully used smoothing methods for short term forecasting of financial time series. HWMS method is a complex expansion of the exponential smoothing method, since it exponentially smooths values for level, trend and seasonality adjustments. However, all the parameters in HWMS models are smoothing factors, which explain nothing much about the series behavior.

Even though Indraji, (2014) and Priyadarshani, et al., (2014) appears to be the first to use ANN approach for coconut price modelling, only Priyadarshani, et al., (2014) has got results in favor of ANN. Priyadarshani et al. (2014) used Generalized Auto Regressive Conditional Heteroskedasticity (GARCH) and Nonlinear Autoregressive neural network with exogenous inputs (NARX) models to forecast retail and producer price of fresh coconuts. The results showed that the NARX model was the most appropriate model to forecast both retail and producer prices of coconut during the study period. NARX neural network is a variant of a recurrent network, which can efficiently be used for modelling non-stationary and nonlinear time series. NARX models can better discover long time dependences than conventional recurrent neural networks but they still have limitations in learning long time dependences due to the "vanishing gradient".

Nyantakyi et al. (2015) examined the individual behavior of the prices of tea, rubber and coconut in Sri Lanka using ARIMA and the combined effects of these prices using Vector Error Correction models (VECM). They have shown that according to the VECM there may be a feedback relationship between all the three series and impulse response analyses revealed that there is a fairly strong correlation between them. Further, the authors concluded that ARIMA $(0,1,3)$ was the best-fitted model for the annual price series of coconut from 1966 to 2009. Ang, (2016) explored the feasibility of Time series Regression with ARIMA noise, Missing observations and Outliers (TRAMO) model to forecast the global price of copra by using the monthly price of copra from January 2000 to June 2016. He concluded that the bestchosen model is ARIMA $(3,1,0)(0,0,0) 12$.

The modelling techniques used in coconut price forecasting were mainly time series models including smoothing techniques such as single exponential, double exponential, HW's method, ARIMA model with or withoutseasonal component, VAR model and ANN approach. Smoothing 
techniques and ARIMA models were comparable and both methods were successful in forecasting coconut prices (Rangoda, et al., 2006). On some occasions, HW smoothing models outperform ARIMA (Elias, 2018) because they can quickly adapt to minor changes in the market condition. However, exponential smoothing methods are essentially methods of fitting a suitable curve to historical data of a given time series and hence they are now supplemented by the other advanced economic forecasting methods (Gujarati and Porter, 2008). Generally, in econometric forecasting, ARIMA is well accepted as a better technique than other considered methods (Meade, 2000; Nochai and Titida Nochai, 2006; Harris, et al., 2012; Jha and Sinha, 2013; Adebiyi, et al., 2014), which is also supported by Rangoda, et al. (2006), Ang, (2016) and Priyanga, et al., (2019) proving that ARIMA is the better method in forecasting coconut prices. However, Ang, (2016) has recommended a multivariate analysis to enhance the reliability of the forecasting because ARIMA is only defined by the present and lagged prices as explanatory variables. According to the literature, prices of coconuts and other coconut-based products are induced by the factors such as cross-price elasticity of coconut oil with respect to other edible oil prices (substitution effect), global market prices and the supply-demand relationship (Das, (1986), Estal, (2014), Jayalath and Weerahewa, (2014)). Therefore, the incorporation of such relationships into the modelling approach has a potential for improvement of applicability and better forecasts.

There are several studies that have used the above discussed time series forecasting techniques in other plantation crops such as tea and rubber. These studies also have provided successful models and prediction outcomes favoring the use of time series methods (Aponsu and Jayasundara, 2012; Hettiarachchi and Banneheka, 2013; Ikonya, et al., 2014; Cherdchoongam \& Rungreunganum, 2016; Induruwage, et al., 2016; Liu and Shao, 2016; Hussain and Ali, 2017). After reviewing several studies on tea price modelling, Gunathilaka and Tularam, (2016) have concluded that VAR model appears to be the more appropriate method for modelling tea prices as it allows to incooperate a group of interacting time series variables to explain the dynamic relationships among these time series in the system. Furthermore, this framework permits to include other variables such as climatic variables to quantify the likely impacts. However, as the real-world prices of agricultural products and their underlying market fluctuations are often non-linear in nature, much attention has focused on ANN in recent years as an alternative technique for forecasting in economics (Li, et al., 2010; Jha and Sinha, 2013). Several studies that have compared the ANN with other time series approaches like ARIMA have proven that ANN performs much better than the other models (Hettiarachchi and Banneheka, 2013; Jha and Sinha, 2013; Hussain and Ali, 2017). ANN allows to modelling complex non-linear relationships between the prices and its determinants such as meterological and seasonal variables, food safety, risk and incertainity etc. (Li, et al., 2010).

Due to time series approaches used, none of the studies above could explain the real reasons/causes for getting a particular forecast, even though the models were able to predict the future with minimum error based on the past observations. However, a vulnerable system like the coconut industry needs to be adjusted for potential uncertainties based on the most influential factors deciding the future prices in different situations. Therefore, the price changes in coconut-based products should be studied together as interdependent sub-systems and modelled based on a systems' approach for a better understanding of the system dynamics. Selection of suitable forecasting methods is very crucial to handle increasing variety and complexity to generate reliable and accurate forecasts. As each method has its limitations depending on the situation, the selection of the forecasting technique should be carefully done to get the maximum accuracy.

Given the complexity of the coconut industry, several scholars have attempted to develop an economic framework to model the industry. De Silva (1985) hypothesized the Sri Lankan coconut industry by adopting a Partial Equilibrium Model (PEM); a condition of economic equilibrium that has taken into consideration only the considered segment of the market to attain an equilibrium, while all other segments of the market were kept constant. However, this study was limited to graphical illustrations as the inadequacy of data prevented estimation of basic coefficients required for the analysis. Considering three major products in the coconut market; culinary nuts, coconut oil and desiccated coconut, Samarajeewa (2002a, $2002 \mathrm{~b}$ ) also estimated a PEM for the coconut market in which the supply and demand relationships in each market were linked using the equilibrium price and the system of equations were econometrically estimated. More recently, 
Pathiraja et al.,(2017) developed and tested an Equilibrium Displacement Model, a type of PEM, for the coconut market. Abeysekara et al.,(2020) re-estimated the PEM adopted by Samarajeewa et al., (2002) to analyze the changing directions of the supply-demand relationships in the coconut market. However, the primary objective of all these studies was to either analyze the economic results of policies affecting the coconut industry or to analyze the economic impact of different climate scenarios. More importantly, PEM models are static and hence do not serve the purpose of price forecasting even though they capture all the equilibrium relationships in the specified market. These can however be used to estimate the economic impact of exogeneous shocks (i.e.policy, climate scenarios, etc.). The PEM equates supply and demand in one or more markets so that prices stabilize at their equilibrium level. Therefore, once calibrated, these can be used to simulate the point forecast of equilibrium price.

\section{Conclusions}

Price movement and volatility forecasting in coconut-based products have been extensively studied using univariate time series techniques. The use of bivariate and multivariate techniques in this domain is minimal. Univariate time series models are easy to handle as they forecast the future by evaluating the past observations (trends and seasonality) of the dependent variable in the model. As they do not consider the interactions between variables, use of these types of models excessively confines the analysis to a single variable, despite many interactions affected in a system of coconut pricing. Univariate models, therefore, are less explicable about the observed changes regardless of the accuracy of the forecast. Nevertheless, various exogenous variables that influence the endogenous variables of the coconut pricing system are evidenced in the experimental literature. Among them, anomalies in weather parameters, substitution factors, import factors, and different government policies may significantly contribute to the system of price determination. Analyzing the consistency of such observational data may also be useful in determining the theoretical relationship between the variables to be used in the modelling. Therefore, the incorporation of influential exogenous factors into the model may yield a better understanding of the situation and uncertainties.

Among the multivariate techniques tested on coconut pricing, VAR and ANN appeared to be the most successful methods. The VAR technique, one of the most successful and flexible models for analyzing multivariate timeseries, has the ability to model the non-structural relationship of coconut price along with other time series variables. ANN models that can model the complex nonlinear relationships between price and its determining factors have been frequently applied in modelling prices of other agricultural commodities and they have provided successful models and prediction outcomes. Several attempts have been made to conceptualize an economic framework to model the coconut industry using PEM, thus provide only a point forecast. However, it is noted that prices, production, climatic variables and other factors as a system have not yet been considered in the coconut price modelling and forecasting and hence appears to be a major gap in the existing studies. Therefore, it is important to extend the existing studies of coconut price modelling and forecasting to include the other interacting variables to generate more explicable forecast values allowing the industry to adapt its uncertain circumstances.

\section{References}

Abeygunawardena, P., Idirisingha, I., \& Ariyawardana, A. 1996. Forecasting of Coconut Prices: A Vector Autoregression Approach. Sri Lankan Journal of Agricultural Sciences, 33: 159-181.

Abeysekara, M. G., \& Pathiraja, P. E. 2019. Effect of tariff on edible oil imports on the behaviour of the Sri Lankan coconut industry-Partial Equilibrium Analysis. Coconut Research Institute of Sri Lanka, Agricultural Economics and Agribusiness Management Division. Unpublished.

Adebiyi, A. A., Adewumi, A., \& Ayo, C. 2014. Comparison of ARIMA and Artificial Neural Networks Models for Stock Price Prediction. Journal of Applied Mathematics, 1-7. Retrieved from http://dx.doi. org/10.1155/2014/614342.

Allen, P. G. 1994. Economic Forecasting in Agriculture. International Journal of Forecasting, 10: 81-135.

Ang, L. C. 2016, 8 17. A forecast of the monthly price of copra using TARMO. An Empirical Paper, De La Salle University Manila, Faculty of the school of Economics. Retrieved 92018 , 
13, from www.academia.edu: http://www. academia.edu/28023803/A_Forecast_ of_the_Monthly_Price_of_Copra_Using_ TRAMO.

Aponsu, G. M., \& Jayasundara, D. 2012. Time Fluctuation Models to Forecast Tea Production, Prices and Exports in Sri Lanka. 13 ${ }^{\text {th }}$ Annual Research Symposium, Colombo: University of Kelaniya.

Asian Pacific Coconut Community. 2016. Coconut Statistical Yearbook. Jakarta: Asian Pacific Coconut Community (APCC).

Brintha, N. K., Samita, S., Abeynayake, N., Idirisingha, I., \& Kumaratunge, A. 2014. Use of Unobserved Components Model for Forecasting Non-stationary Time Series: A Case of Annual National Coconut Production in Sri Lanka. Tropical Agricultural Research, 25(4): 523-531.

Cherdchoongam, S., \& Rungreunganum, V. 2016. Forecasting Prices of Natural Rubber in Thailand Using ARIMA Model. KMUTNB International Journal of Applied Science Technology, 9(4): 271-277.

Das, P. K. 1986. Movement of Wholesale Prices of Coconuts, Copra and Coconut Oil in Kerala during the last Two and Half Decades. Journal of Plantation Crops, 14(2): 105-114.

Deaton, A., \& Laroque, G. 1992. On the Behaviour of Commodity Prices. The Review of Economic Studies, 59(1): 1-23. Retrieved from http://www.jstor.org/ stable/2297923.

Elias, G. 2018. Economics of coconut productsan analytical study. Commerce Spectrum, 5(2): 39-44.

Estal, B. R. 2014. Pricing Movements of Copra in the Philippines. In Handbook on the Emerging Trends in Scientific Research (pp. 527-534). Malaysia: PAK Publishing Group.

FAO. 2017. FAOSTAT. Retrieved 11 12, 2018, from http://www.fao.org/faostat/en/\#data.

Gujarati, D. N., \& Porter, D. 2008. Basic Econometrics (5 ed.). New York: McGraw-Hill/Irwin.
Gunathilaka, R. P., \& Tularam, G. 2016. The Tea Industry and a Review of Its Price Modelling in Major Tea Producing Countries. Journal of Management and Strategy, 7(1): 21-33.

Harris, E., Aziz, A., \& Avuglah, R. 2012. Modeling Annual Coffee Production in Ghana Using ARIMA Time Series Model. International Journal of Business and Social Research, 2(7): 175-186.

Harvey, A. C. 1993. Time Series Models (2 ed.). Cambridge: The MIT Press.

Hettiarachchi, H. A., \& Banneheka, B. 2013. Time Series Regression and Artificial Neural Network Approaches for Forecasting Unit Price of Tea at Colombo Auction. Journal of National Science Foundation Sri Lanka. 41(1): 35-40.

Hussain, M. N., \& Ali, A. 2017. Forecasting of Pakistan's Import Prices of Black Tea Using ANN and SARIMA Model. International Review of Management and Business Research, 6(4): 1372-1382.

Indraji, K. N. 2014. Price forecast models for coconut and coconut oil. Thesis Submitted in partial fulfillment of the requirement for the degree of Master of Science in Agricultural Statistics, Faculty of Agriculture, Kerala Agricultural University, Department of Agricultural Statistics.

Induruwage, D., Tilakaratne, C., \& Rajapaksha, S. 2016. Forecasting Black Tea Auction Prices by Capturing Common Seasonal Patterns. Sri Lankan Journal of Applied Statistics, 16(3): 195-214.

Jayalath, K. V., \& Weerahewa, J. 2014. Tariff Endogeneity: Effect of Export Price of Desiccated Coconuts on Edible Oil Market in Sri Lanka. Tropical Agricultural Research, 25(4): 476-486.

Jha, G. K., \& Sinha, K. 2013. Agricultural Price Forecasting Using Neural Network Model: An Innovative Information Delivery System. Agricultural Economics Research Review, 26(2): 229-239.

Just, R. E. 1993. Discovering production and Supply Relationships: Present Status and Future Opportunities. Review of 
Marketing and Agricultural Economics. 61, 11-40.

Kalidas, K., Darthiya, M., Malathi, P., \& Thomas, L. 2014. Organic Coconut Cultivation in India -Problems \& Prospects. International Journal of Scientific Research, 3(6): 14-15.

Li, G.-q., Xu, S.-w., \& Li, Z.-m. 2010. Short-Term Price Forecasting for Agro-Products using Artificial Neural Networks. Agriculture and Agricultural Science Procedia I, (pp. 278-287).

Liu, H., \& Shao, S. 2016. India's Tea Price Analysis Based on ARMA Model. Modern Economy, 7: 118-123. Retrieved from http://dx.doi. org/10.4236/me.2016.72014.

Makridakis, S., Hibon, M., \& Moser, C. 1979. Accuracy of Forecasting: An Empirical Investigation. Journal of the Royal Statistical Society. Series A (General), 142(2): 97-145. DOI: 10.2307/2345077.

Meade, N. 2000. Evidence for the Selection of Forecasting Methods. Journal of Forecasting, 19: 515-535.

Nampoothiri, C. K., \& Balakrishna, N. 2000. Threshold Autoregressive Model for a Time Series Data. Journal of Indian Soc. Agricultural Statistics, 53(2): 151-160.

Nampoothiri, K. 2001. Modelling and Analysis of some Time Series. M.Phil Thesis, Cochin University of Science and Technology, Department of Statistics.

Naveena, K., Rathod, S., Shukla, G., \& Yogish, K. J. 2014. Forecasting of coconut production in India: A suitable time series model. International Journal of Agricultural Engineering, 7(1): 190-193.

Nochai, R., \& Titida Nochai. 2006. ARIMA model for Forecasting Oil Palm Price. Proceedings of the $2^{\text {nd }}$ IMT-GT Regional Conference on Mathematics, Statistics and Applications (pp. 1-7). Penang: University Sains Malaysia.

Nyantakyi, K. A., Peiris, B., \& Gunaratna, L. 2015. Analysis of the Interrelationships between the Prices of Sri Lankan Rubber, Tea and Coconut Production Using Multivariate Time Series. Advances in
Economics and Business, 3(2): 50-56. DOI: 10.13189/aeb.2015.030203.

Pathiraja, E., Griffith, G., Farquharson, R., \& Robert, F. 2017. Specifying and Testing an Equilibrium Displacement Model of the Coconut Market in Sri Lanka. Australasian Agribusiness Review, 25(Paper 5): 55-86.

Pathiraja, P., Griffith, G. R., Farquharson, R. J., \& Faggin, R. 2015. The Sri Lankan Coconut Industry: Current Status and Future Prospects in a Changing Climate. Australasian Agribusiness Perspectives, (Paper 106): 1-23.

Peiris, T. S., Thattil, R., \& Mahindapala, R. 1995. An Analysis of the Effect of Climate and Weather on Coconut (Cocos nucifera). Experimental Agriculture, 31: 451-460.

Peterson, H. H., \& Tomek, W. 2000. Implications of Deflating Commodity Prices for Time-Series Analysis. NCR-134 Conference on Applied Commodity Price Analysis, Forecasting, and Market Risk Management. Chicago.

Priyadarshani, G. A., Thilakaratne, C. D., Sunethra, A. A., \& Oshani, D. K. 2014. Modeling Monthly Coconut Prices in Sri Lanka using Non-Linear Time Series Models. Proceedings of the International Statistics Conference 2014- IASSL, (p. 229). Sri Lanka.

Priyanga, V., Lazarus, P., Mathew, S., \& Joseph, B. 2019. Forecasting Coconut Oil Price Using Auto Regressive Integrated Moving Average (ARIMA) Model. Journal of Pharmacognosy and Phytochemistry, 8(3): 2164-2169.

Rangoda, B. D., Abeywickrama, L. M., \& Fernando, M. T. 2006. An analysis of different forecasting models for prices of coconut products in Sri Lanka. Proceedings of the Third Academic Sessions (pp. 8-15). University of Ruhuna.

Rethinam, P. 2005. Asian and Pacific Coconut Community Activities, Achievements and Future Outlook. In S. Adkins, M. Foale, \& Y. Samosir (Ed.). Coconut revival: new possibilities for the "Tree of Life", Proceedings of the International Coconut Forum (pp. 15-21). Cairns, Australia: 
Australian Centre for International Agricultural Research.

Samarajeewa, S. R. 2002a. An Econometric Analysis of Consumer Demand for Coconuts in Sri Lanka. CORD, Coconut Research and Development Journal, 18(2): 24-28.

Samarajeewa, S. R. 2002b. The Economic Impact of Selected Government Interventions on the Coconut Sector in Sri Lanka. Unpublished MPhil Thesis, University of Peradeniya, Post Graduate Institute of Agriculture.

Samarajeewa, S. R., Weerahewa, J., \& Gunathilake, H. M. 2002. Tariff Policy Liberalisation in Edible Oil Market and Its Implications on the Coconut Producers in Sri Lanka.
Tropical Agricultural Research, 14: 317-326.

Silva, H. W. 1985. An Economic Analysis of Government Intervention Measures in the Coconut Industry of Sri Lanka. CORD, Coconut Research and Development Journal, 1(1): 40-50.

Sri Lanka Export Development Board. 2017. Growth of Demand for Coconut in the Global Market. Retrieved 11 4, 2018, from https:// www.srilankabusiness.com/blog/growthof-global-demand-for-coconut.html.

Taylor, H. C. (1924). Agricultural Forecasting. American Journal of Agricultural Economics, 6(2): 156-163. doi:https://doi. org/10.2307/1229808. 